\title{
Brief communication: Improved measurement of ice layer density in seasonal snowpacks
}

\author{
Tom Watts ${ }^{1}$, Nick Rutter ${ }^{1}$, Peter Toose ${ }^{2}$, Chris Derksen $^{2}$, Melody Sandells ${ }^{3, a}$, and John Woodward ${ }^{1}$ \\ ${ }^{1}$ Department of Geography, Northumbria University, Newcastle upon Tyne, NE1 8ST, UK \\ ${ }^{2}$ Climate Research Division, Environment Canada, Toronto, Canada \\ ${ }^{3}$ National Centre for Earth Observation, University of Reading, Reading, RG6 6AL, UK \\ ${ }^{a}$ now at: CORES Science and Engineering Limited, Victoria Garesfield, UK \\ Correspondence to: Nick Rutter (nick.rutter@northumbria.ac.uk)
}

Received: 6 October 2015 - Published in The Cryosphere Discuss.: 2 November 2015

Revised: 28 July 2016 - Accepted: 15 August 2016 - Published: 14 September 2016

\begin{abstract}
The microstructure and density of ice layers in snowpacks is poorly quantified. Here we present a new field method for measuring the density of ice layers caused by melt or rain-on-snow events. The method was used on 87 ice layer samples taken from natural and artificial ice layers in the Canadian Arctic and mid-latitudes. Mean measured ice layer density was $909 \pm 28 \mathrm{~kg} \mathrm{~m}^{-3}$ with a standard deviation of $23 \mathrm{~kg} \mathrm{~m}^{-3}$, significantly higher than values typically used in the literature.
\end{abstract}

\section{Introduction}

Ice structures form in snowpacks during melt or rain-onsnow events (Colbeck, 1991). Rain either freezes on contact with the surface of the snowpack, or water refreezes within the snowpack to form ice layers, lenses, crusts, columns, or basal ice layers (Gray and Male, 1981). Strong intercrystalline bonds created from refreezing of liquid water lead to the formation of cohesive ice structures (Fierz et al., 2009). Permeability of ice layers to liquid water and gas is vastly reduced compared to snow (Albert and Perron Jr., 2000; Colbeck and Anderson, 1982). Impermeable layers are identifiable because pores do not connect within the ice formation, and the granular snowpack structure is missing (Fierz et al., 2009). Ice layers differ from melt-freeze crusts (often referred to as "ice crusts") and ice lenses; melt-freeze crusts are always permeable and have a coarse-grained granular snow-like structure (Colbeck and Anderson, 1982). Ice lenses can be impermeable, do not have a granular structure and are spatially discontinuous. Similarly to ice lenses, ice layers can be impermeable and do not have a granular structure; however, ice layers are continuous (Fierz et al., 2009).

Ice layers introduce uncertainty into the performance of snow microwave emission models (Rees et al., 2010), which are an important component of satellite-derived snow water equivalent (SWE) retrieval algorithms (Takala et al., 2011). The radiometric influence of even thin ice layers poses a significant challenge for physical and semi-empirical snow emission models, which can treat ice layers either as coarsegrained snow (Mätzler and Wiesmann, 1999) or as planar (flat and smooth) ice layers (Lemmetyinen et al., 2010). Uncertainties attributed to not knowing the density of ice layers are greater than any other parameter in snow emission models (Durand et al., 2008). Consequently, development and evaluation of snow emission models are hindered by poorly quantified field measurements of microstructure and properties of ice layers (Montpetit et al., 2012).

Pure ice density ranges from $916 \mathrm{~kg} \mathrm{~m}^{-3}$ at $0^{\circ} \mathrm{C}$ (Lonsdale, 1958) to $922 \mathrm{~kg} \mathrm{~m}^{-3}$ at $-40^{\circ} \mathrm{C}$ (La Placa and Post, 1960). Only limited field measurements of ice layer densities have previously been attempted. Ice layer density measurements taken in the Canadian Arctic by submerging pieces of melt-freeze crust into oil resulted in a range of densities from 630 to $950 \mathrm{~kg} \mathrm{~m}^{-3}$ (Marsh, 1984). Ice layer densities of 400 to $800 \mathrm{~kg} \mathrm{~m}^{-3}$ were measured using a snow fork, which measures the dielectric properties of snow around $1 \mathrm{GHz}$ (Sihvola and Tiuri, 1986) in seasonal snow on the Greenland ice sheet (Pfeffer and Humphrey, 1996). The results from these studies vary drastically, and a quantitative assessment of the error 


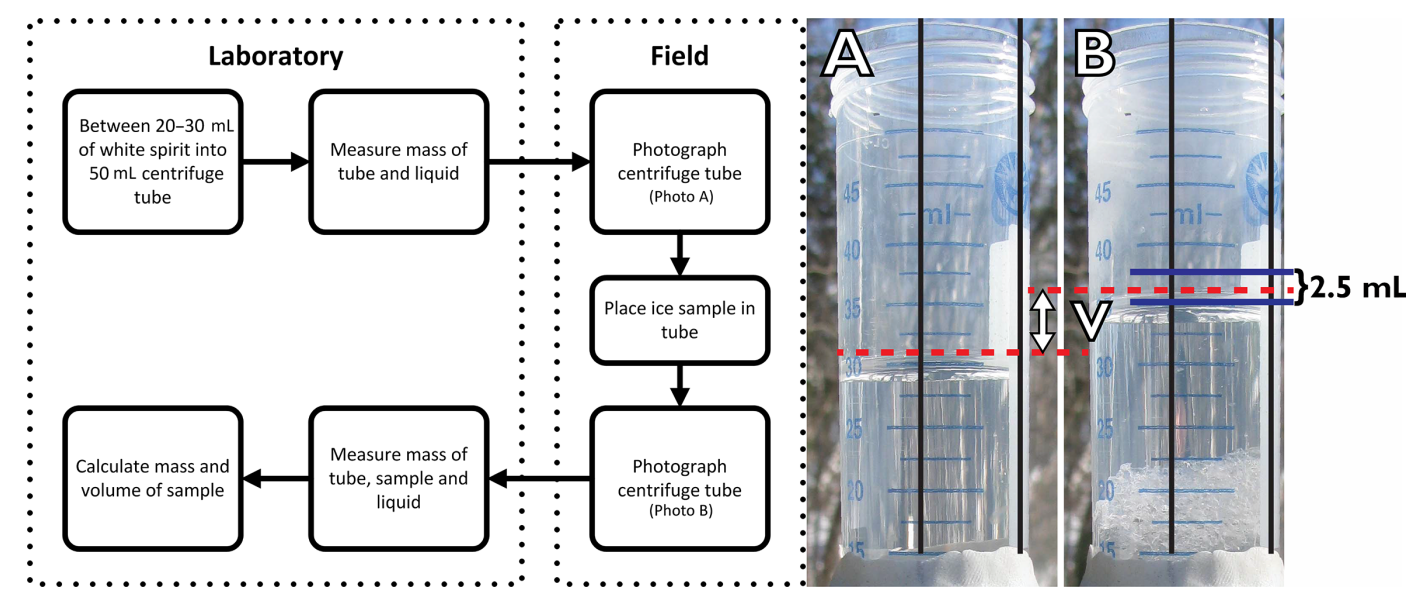

Figure 1. Flow chart describing the methodology to measure densities of ice layers from a snowpack. Photographs show an example pair of photos used in the calculation of ice sample volume. "A" taken before the sample was added and "B" taken after. "V" is equal to the volume of the ice sample. Black lines are guides added to help assess the quality of the photos.

in measurement techniques is absent. Consequently, the aim of this paper is to describe a newly developed field measurement technique for measuring ice layer density and to present density measurements made in Arctic and mid-latitude snowpacks.

\section{Method}

\subsection{Development of ice density measurement method}

A new laboratory and field-based method (Fig. 1) was developed to measure the density of ice layers found in seasonal snow, based on volumetric displacement. The basic principle is that when an ice layer sample is submerged in a vessel of liquid, calculating the volume displacement and sample mass will yield an estimate of density. The mass of a sealed $50 \mathrm{~mL}$ centrifuge tube with $2.5 \mathrm{~mL}$ graduations containing white spirit (sometimes termed "mineral spirits") was measured with a precision of $\pm 0.001 \mathrm{~g}$ under laboratory conditions before entering the field. White spirit is immiscible with water and has a low freezing point $\left(-70^{\circ} \mathrm{C}\right)$, eliminating potential sample melt. White spirit also has a low density $\left(650 \mathrm{~kg} \mathrm{~m}^{-3}\right)$, making it likely that the ice sample would sink and be completely submerged. In the field the centrifuge tube was held by a fixed, levelled, mounting system within the macro setting range of a compact camera. Each camera image was centred on a visible datum on the mounting system to ensure the camera was correctly focused. Images were captured before and after each ice sample was submerged as shown in Fig. 1.

In each image three positions were identified during postprocessing: the liquid level, the graduation above the liquid level and the graduation below the liquid level. Pixel coordinates of these positions were recorded and the proportional height of the liquid level between the upper and lower graduation was translated to a volume at a higher resolution than the centrifuge tube graduations alone would allow. After images were taken, the centrifuge tube containing the sample was sealed and the change in mass was measured on return to the laboratory.

\subsection{Methodological error}

Ice layers found in snowpacks are very difficult to accurately and consistently re-create under laboratory conditions. Therefore to assess the accuracy of the ice density measurement technique, ball bearings of known volume were measured. Stainless steel ball bearings were used (manufactured to a diameter of $\left.1 \pm 2.5 \times 10^{-5} \mathrm{~cm}\right)$, resulting in a volume of $0.5236 \pm 0.0004 \mathrm{~cm}^{3}$. The volume of ball bearings was calculated from before and after images of 10 ball bearings submerged in the centrifuge tube. The expected total volume of all ball bearings of approximately $5.236 \mathrm{~cm}^{3}$ is comparable to the mean volume of ice samples collected. Of 134 samples, each consisting of 10 ball bearings, the mean volume was $5.045 \mathrm{~cm}^{3}$. Volume measurements were normally distributed and an error value based on \pm 1 standard deviations was calculated, resulting in a systematic volume measurement error or bias of $-0.19 \mathrm{~cm}^{3}$.

Identifying the precise height of the surface of the liquid between the graduation markings on the cylinder is limited by the quality of the camera focus and resolution of the camera. Based on carrying out 10 repeat measurements on 10 centrifuge tube photos the (mean) error was found to be $\pm 0.125 \mathrm{~cm}^{3}$ in each volume measurement photo, equating to a random root-mean-square error in the measurement of the ice sample volume of $\pm 0.18 \mathrm{~cm}^{3}$ (error $=$ $\sqrt{0.125^{2}+0.125^{2}}$ ), as each volume measurement involves reading the volume from two photos. 
Table 1. Measurements of ice layer density bubble size and thickness (all sizes in millimetres, all densities in $\mathrm{kg} \mathrm{m}^{-3}$ ). $n$ is number of samples, $n<0.1$ is the number of samples with a bubble diameter of less than $0.1 \mathrm{~mm}$. All ice layer density values have been corrected to account for the measured $-0.19 \mathrm{~cm}^{3}$ bias in volume.

\begin{tabular}{ll|cccc|ccc|ccc}
\hline & & \multicolumn{4}{|c|}{ Bubble diameter } & \multicolumn{3}{c}{ Layer thickness } & \multicolumn{3}{c}{ Density } \\
& Type & $n$ & $n<0.1$ & Mean & SD & $n$ & Mean & SD & $n$ & Mean & SD \\
\hline Care & Natural & - & - & - & - & 29 & 8 & 0.6 & 29 & 906 & 17 \\
North Bay & Natural & 14 & 4 & 0.16 & 0.12 & 15 & 3 & 0.6 & 15 & 890 & 21 \\
& Artificial & 12 & 6 & 0.08 & 0.03 & 15 & 5 & 0.9 & 15 & 921 & 18 \\
Inuvik & Artificial & - & - & - & - & 28 & 2 & 0.5 & 28 & 915 & 26 \\
Overall & - & 26 & 10 & 0.12 & 0.1 & 87 & 5 & 2.7 & 87 & 909 & 23 \\
\hline
\end{tabular}

To estimate the potential impact of the uncertainty in volume measurement on samples taken in the field, the random $\left( \pm 0.18 \mathrm{~cm}^{3}\right)$ volume measurement error from the ball bearing experiment was applied to a theoretical ice sample volume of $4.89 \mathrm{~cm}^{3}$ (chosen as it was the estimated smallest sample volume taken during field trials) and mass of $4.53 \mathrm{~g}$ (equating to a density of $916 \mathrm{~kg} \mathrm{~m}^{-3}$ ). This volume error from the ball bearing experiment translated into an observed volume of $4.53-4.89 \mathrm{~cm}^{3}$ (i.e. $4.71 \pm 0.18 \mathrm{~cm}^{3}$ ). Assuming no error in the mass balance (precision of $\pm 0.001 \mathrm{~g}$ ), the upper density value (minimum volume) was $951 \mathrm{~kg} \mathrm{~m}^{-3}$ and the lower density value (maximum volume) was $881 \mathrm{~kg} \mathrm{~m}^{-3}$, representing an uncertainty in density of $\pm 35 \mathrm{~kg} \mathrm{~m}^{-3}$ or $4 \%$.

\subsection{Field measurements}

During the winter of 2013, ice layer density measurements were collected at three sites in Canada: North Bay, Ontario $\left(46.33^{\circ} \mathrm{N}, 79.31^{\circ} \mathrm{W}\right)$, between 8 and 9 February; Canadian Centre for Atmospheric Research (CARE), Egbert, Ontario $\left(44.23^{\circ} \mathrm{N}, 79.78^{\circ} \mathrm{W}\right)$, on 25 February; and Trail Valley Creek, Inuvik, North West Territories $\left(68.72^{\circ} \mathrm{N}, 133.16^{\circ} \mathrm{W}\right)$, on 9 April. Ice layers were removed from the surrounding snow and broken to size using a scraper.

In North Bay (NB), an artificial ice layer was created by spraying water onto the surface of the snowpack. Artificial ice layers have been created in previous work (Montpetit et al., 2012), so it is important to know whether their characteristics differ from naturally occurring ice layers. A natural ice layer covering the entire clearing was also present lower within the snowpack (formed by $2 \mathrm{~mm}$ of rain on $30 \mathrm{Jan}$ uary). Density, bubble diameter, and thickness measurements of both natural and artificial ice layers were made; whenever bubbles were visible their diameters were measured using a field microscope and snow grain card, at a resolution of $0.1 \mathrm{~mm}$. Very small bubbles, with a diameter of $<0.1 \mathrm{~mm}$ were recorded as being visible although a diameter could not be applied to them. Layer thickness was measured to a resolution of $1 \mathrm{~mm}$ for each sample.

At CARE, measurements were conducted in an open, grass-covered field. A spatially continuous ice layer formed over an area of at least $200 \times 100 \mathrm{~m}$ in the $10 \mathrm{~cm}$ deep snow- pack as a result of above-freezing daytime temperatures for a period of 4 days prior to measurement. Ice layer thickness and densities were measured in the same manner as in North Bay.

In Inuvik, water was sprayed onto a $30 \mathrm{~cm}$ tundra snowpack when air temperatures were approximately $-25^{\circ} \mathrm{C}$ to form an artificial ice layer on the surface of the snowpack. Water was sprayed over an area of $1 \mathrm{~m}^{2}$, concentrating the spraying towards one edge, which created ice thicknesses between 1 and $6 \mathrm{~mm}$.

\section{Results}

\subsection{Ice layer density}

Mass, volume and density measurements were made of 86 samples of ice layers and are summarized in Table 1 and Fig. 2. After measurements were corrected for bias the mean sample volume was $6.4 \mathrm{~cm}^{3}$. After the random error of $\pm 0.18 \mathrm{~cm}^{3}$ was applied to the volume measurements, an uncertainty of $\pm 28 \mathrm{~kg} \mathrm{~m}^{-3}$ was calculated. Ice layer densities varied between 841 and $980 \mathrm{~kg} \mathrm{~m}^{-3}$, with an overall mean of $909 \mathrm{~kg} \mathrm{~m}^{-3}$ and standard deviation of $23 \mathrm{~kg} \mathrm{~m}^{-3}$. A Kolmogorov-Smirnov test showed natural ice layers were significantly less dense than artificial ones, although the difference was within methodological error. The results from Inuvik show some physically unreasonable high outlying measured densities (Fig. 2). Mass measurements at Inuvik were made outside, and whilst care was taken to ensure the balance was level and condensation was cleaned from the balance as it formed, these cannot be ruled out as sources of error.

\subsection{Ice layer bubble size and thickness}

Table 1 summarizes the measurement of ice layer thickness and bubble size. In some cases bubbles were visible in the ice layer but were not large enough to be measured using the field microscope. These were noted as $<0.1 \mathrm{~mm}$ in Table 1. For the purpose of calculating the mean and standard deviation of the bubble distribution a value of $0.05 \mathrm{~mm}$ was 


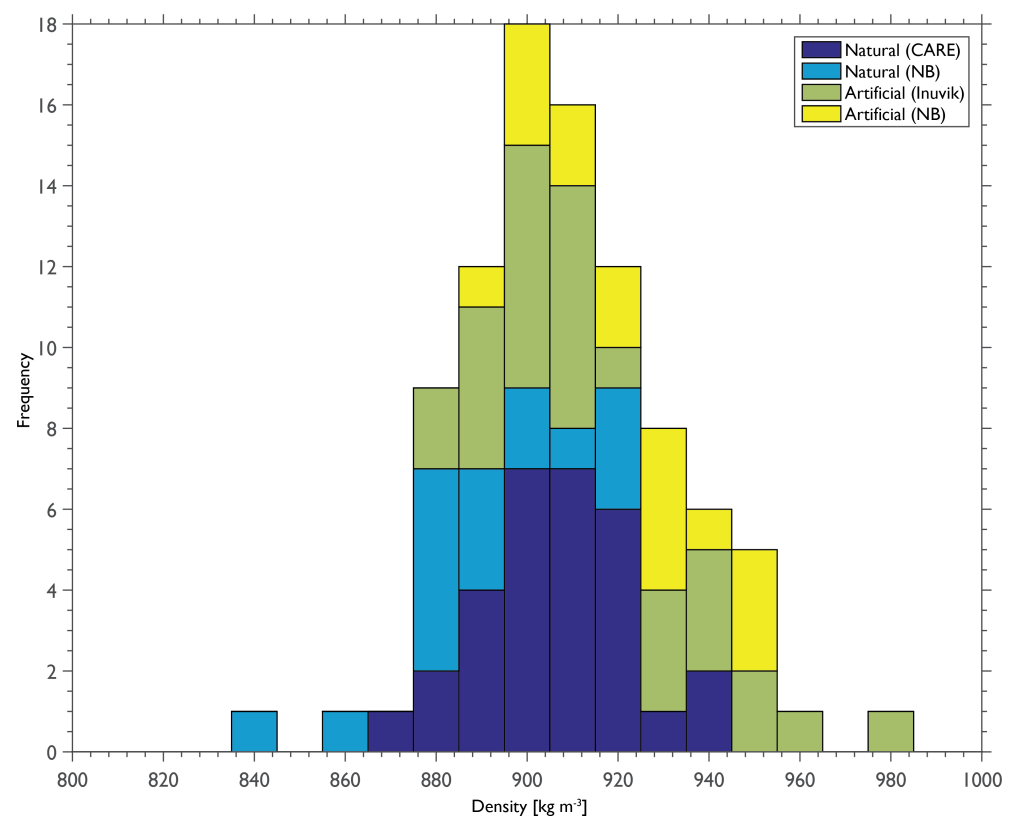

Figure 2. Summary of ice layer density measurements. Stacked histogram showing frequency of each density measurement, colours show distribution of artificial and natural ice layers across multiple sites.

applied to these bubbles. There was no significant correlation between ice layer thickness and bubble diameter $(p<0.01)$.

\subsection{Error analysis}

Three sources of error were quantified in the measurement of ice layer density: (1) systematic error and (2) random error in the volumetric measurement of the ice samples, which would apply to any object measured using this method (both discussed in Sect. 2.2), as well as (3) error from sample porosity, which applies only to the measurement of ice layer density. The measured ice layers had a closed porosity, where layers contained bubbles that were not connected in a porous structure. A greater volume of bubbles in the sample reduces the external dimensions and volume of the sample. Here we refer to this reduction in volume caused by the presence of bubbles as effective porosity, represented by a dimensionless fraction which represents the proportion of sample volume, which is available for liquid to flow through.

The influence of effective porosity on the ice layer density measurements was quantitatively evaluated by numerically modelling the bubbles as spheres within cuboid ice layer samples. This method assumes that the ice layer is solid ice containing bubbles rather than a granular snow-like structure. For a theoretical ice sample of size $10 \mathrm{~mm} \times 10 \mathrm{~mm} \times$ $10 \mathrm{~mm}$ the sample density was increased in increments of $0.01 \mathrm{~kg} \mathrm{~m}^{-3}$ from 600 to $916 \mathrm{~kg} \mathrm{~m}^{-3}$, and effective porosity was measured through the sample by taking slices at $0.1 \mathrm{~cm}$ intervals.

The relationship between effective porosity and density $(\rho)$ for this bubble and sample size is linear, and the effec- tive porosity $\left(\phi_{\text {eff }}\right)$ is found using

$\phi_{\text {eff }}=-0.00016 \rho+0.14$.

Mean bubble diameter and standard deviation were calculated from all samples. The root-mean-square error of Eq. (1) was 0.0007 with an $r^{2}$ value of 0.998 .

The impact of effective porosity on the samples was calculated by assuming a sample width of $2 \mathrm{~cm}$ (the width of the centrifuge tube). As the density of the sample decreased, volume error from effective porosity in the sample ranged from $6.5 \times 10^{-5}$ to $1 \times 10^{-3} \mathrm{~cm}^{3}$. The mean increase using either the maximum or minimum value for density in the effective porosity calculations was $1.42 \times 10^{-6} \mathrm{~cm}^{3}$. The maximum random error $\left( \pm 0.18 \mathrm{~cm}^{3}\right)$, the volume measurement bias reflecting systematic error $\left(-0.19 \mathrm{~cm}^{3}\right)$, and the effective porosity correction were applied to each volume measurement. The maximum range of density was calculated for each sample and the effective porosity was negligible (less than $0.001 \mathrm{~cm}^{3}$ ). Overall the measurements of ice layer density $\left(909 \pm 28 \mathrm{~kg} \mathrm{~m}^{-3}\right)$ were not significantly different to the actual density of pure ice $916-922 \pm 28 \mathrm{~kg} \mathrm{~m}^{-3}$ between 0 and $-40^{\circ} \mathrm{C}$ (Lonsdale, 1958; La Placa and Post, 1960).

\section{Discussion and conclusion}

New laboratory and field protocols were used to produce direct measurements of ice layer density including a thorough assessment of measurement uncertainty. Measurements of natural and artificially made ice layers produced an average density of $909 \pm 28 \mathrm{~kg} \mathrm{~m}^{-3}$, where uncertainty is a function of 
the random error in the method used to measure the volume of the ice samples. Effective porosity of ice layers was estimated using observations of bubble size and was deemed to be too low to impact the accuracy of the method. Our measured density values are higher than those previously measured by Marsh (1984) (mean $800 \mathrm{~kg} \mathrm{~m}^{-3}$ ) and Pfeffer and Humphrey (1996) (400 to $800 \mathrm{~kg} \mathrm{~m}^{-3}$ ). It is unclear whether previous studies measured the density of ice layers that were permeable, including thin, non-continuous ice layers. Here only impermeable ice layers were measured and this may explain the density differences between studies. In addition, artificially created ice layers had a higher density than natural ice layers (Table 1). A possible reason for this is that the artificial ice layers were created on the surface of the snowpack, which is likely to experience lower air temperatures than naturally formed ice layers within the snowpack.

Densification and ice formation impacts passive microwave brightness temperatures at the satellite scale (Grody, 2008). Consequently, the evolution of ice structures is important in characterization of snowpack microwave signatures and may play an important role in ice layer detection algorithms. However, snow microwave emission models are currently unable to accurately model ice layers (Rees et al., 2010). Some snow emission models (e.g. Wiesmann and Mätzler, 1999; Picard et al., 2013) include a parameter for ice layer density, which has previously been very poorly constrained and is a large source of uncertainty in emission models (Durand et al., 2008) and remote sensing data assimilation applications (Langlois et al., 2012). Consequently, new ice layer density measurements presented here provide a means to reduce uncertainty in future snow radiative transfer modelling.

\section{Data availability}

The data sets are available in the Supplement.

\section{The Supplement related to this article is available online at doi:10.5194/tc-10-2069-2016-supplement.}

Acknowledgements. The authors would like to thank Arvids Silis for assistance throughout the fieldwork, Gail and Andrew Rees for support during data collection in North Bay, Dave Halpin and Dave Thomas for help facilitating field and lab work, and James Reeve for support with experiment design. This work was supported by a Northumbria University RDF studentship (Tom Watts) and the Natural Science and Engineering Research Council (Discovery Grant: Chris Derksen); field activities were funded by Environment Canada.

Edited by: M. Schneebeli

Reviewed by: C. Fierz and one anonymous referee

\section{References}

Albert, M. R. and Perron Jr., F. E.: Ice layer and surface crust permeability in a seasonal snowpack, Hydrol. Process., 14, 3207-3214, 2000.

Colbeck, S. C.: The layered character of snow covers, Rev. Geophys., 29, 81-96, 1991.

Colbeck, S. C. and Anderson, E. A.: The permeability of melting snow, Water Resour. Res., 18, 904-908, 1982.

Durand, M. T., Kim, E. J., and Margulis, S. A.: Quantifying uncertainty in modeling snow microwave radiance for a mountain snowpack at the point-scale, including stratigraphic effects, IEEE T. Geosci. Remote, 46, 1753-1767, 2008.

Fierz, C., Armstrong, R. L., Durand, Y., Etchevers, P., Greene, E., McClung, D. M., Nishimura, K., Satyawali, P. K., and Sokratov, S. A.: The international classification for seasonal snow on the ground, UNESCO/IHP, Paris, 2009.

Gray, D. M. and Male, D. H.: Handbook of Snow, The Blackburn Press, Caldwell, New Jersey, 1981.

Grody, N.: Relationship between snow parameters and microwave satellite measurements: Theory compared with advanced microwave sounding unit observations from 23 to $150 \mathrm{GHz}$, J. Geophys. Res.-Atmos., 113, 1-17, 2008.

Langlois, A., Royer, A., Derksen, C., Montpetit, B., Dupont, F., and Goïta, K.: Coupling of the snow thermodynamic model SNOWPACK with the Microwave Emission Model for Layered Snowpacks (MEMLS) for subarctic and arctic snow water equivalent retrievals, Water Resour. Res., 48, 819-821, 2012.

La Placa, S. J. and Post, B.: Thermal expansion of ice, Acta Crystallogr., 13, 503-505, 1960.

Lemmetyinen, J., Pulliainen, J., Rees, A., Kontu, A., and Derksen, C.: Multiple-layer adaptation of HUT Snow Emission Model: comparison with experimental data, IEEE T. Geosci. Remote, 48, 2781-2794, 2010.

Lonsdale, D. K.: The structure of ice, P. Roy. Soc. Lond. A Mat., 247, 424-434, 1958.

Marsh, P.: Wetting front advance and freezing of meltwater within a snow cover: 1. Observations in the Canadian Arctic, Water Resour. Res., 20, 1853-1864, 1984.

Mätzler, C. and Wiesmann, A.: Extension of the microwave emission model of layered snowpacks to coarse-grained snow, Remote Sens. Environ., 325, 317-325, 1999.

Montpetit, B., Royer, A., Roy, A., Langlois, A., and Derksen, C.: Snow microwave emission modeling of ice lenses within a snowpack using the microwave emission model for layered snowpacks, IEEE T. Geosci. Remote, 51, 4705-4717, 2012.

Pfeffer, W. T. and Humphrey, N. F.: Determination of timing and location of water movement and ice-layer formation by temperature measurements in sub-freezing snow, J. Glaciol., 42, 292 304, 1996.

Picard, G., Brucker, L., Roy, A., Dupont, F., Fily, M., Royer, A., and Harlow, C.: Simulation of the microwave emission of multilayered snowpacks using the Dense Media Radiative transfer theory: the DMRT-ML model, Geosci. Model Dev., 6, 1061-1078, doi:10.5194/gmd-6-1061-2013, 2013.

Rees, A., Lemmetyinen, J., Derksen, C., Pulliainen, J., and English, M.: Observed and modelled effects of ice lens formation on passive microwave brightness temperatures over snow covered tundra, Remote Sens. Environ., 114, 116-126, 2010. 
Sihvola, A. and Tiuri, M.: Snow fork for field determination of the density and wetness profiles of a snow pack, IEEE T. Geosci. Remote, GE-24, 717-721, 1986.

Takala, M., Luojus, K., Pulliainen, J., Derksen, C., Lemmetyinen, J., Kärnä, J.-P., Koskinen, J. T., and Bojkov, B.: Estimating northern hemisphere snow water equivalent for climate research through assimilation of space-borne radiometer data and groundbased measurements, Remote Sens. Environ., 115, 3517-3529, 2011.
Wiesmann, A. and Mätzler, C.: Microwave emission model of layered snowpacks, Remote Sens. Environ., 70, 307-316, 1999. 